Acta Agroph., 2019, 26(1), 67-78

doi: $10.31545 /$ aagr/109187

\title{
IMPACT OF SEED LIGHT STIMULATION ON THE MECHANICAL STRENGTH AND PHOTOSYNTHETIC PIGMENTS CONTENT IN THE SCORZONERA LEAVES
}

\author{
Anna Ciupak ${ }^{1}{ }^{\circledR}$, Agata Dziwulska-Hunek ${ }^{1} @$, Marcela Krawiec ${ }^{2}$, \\ Bożena Gładyszewska ${ }^{1}$ (D) \\ ${ }^{1}$ Department of Biophysics, University of Life Sciences in Lublin \\ ${ }^{2}$ Unit of Plant Nutrition, Institute of Horticultural Production, University of Life Sciences in Lublin \\ Głęboka 28, 20-612, Lublin, Poland
}

\begin{abstract}
The leaves of scorzonera are vulnerable to mechanical damage due to heavy rainfall or wind. The aim of the study was to determine the impact of pre-sowing exposure of scorzonera seeds to laser light on the mechanical strength of the leaves and the content of photosynthetic pigments. The research material consisted of scorzonera leaves obtained from seeds treated with $\mathrm{He}-\mathrm{Ne}$ laser light at the wavelength of $632.8 \mathrm{~nm}$, surface power density of $5 \mathrm{~mW} \mathrm{~cm}^{-2}$, and exposure time of 1, 5, 10, and 30 minutes. Young's modulus measurements showed that the leaves of the plants grown from seeds subjected to laser light stimulation were characterized by better mechanical strength compared to the leaves of the control. The highest values of the Young's modulus were recorded for scorzonera plants grown from seeds subjected to laser light exposure for 10 minutes. Exposure to light for a period of 1, 5 and 30 minutes significantly affected the content of chlorophylls and carotenoids in the leaves relative to the control. The largest increase in the content of photosynthetic pigments was recorded for 1 minute. The improvement in the mechanical strength of scorzonera leaves may reduce their vulnerability to mechanical damage during vegetation.
\end{abstract}

Key w ord s: laser light, scorzonera, leaves, Young's modulus, tensile test, photosynthetic pigments

\section{INTRODUCTION}

Scorzonera hispanica is cultivated in Europe mainly as a root vegetable. The plant produces long, edible roots with dark brown skin and cream-coloured flesh, which are usually eaten boiled. Young scorzonera leaves are also edible and are considered nutritious. They contain high amounts of potassium, iron, magnesium, vitamin C, polyphenol acids and carotenoids (Dolota and Dąbrowska 2004). 
Green leafy vegetables are used in many countries around the world as a source of fibre, vitamins and minerals (Jiménez-Aguilar and Grusak 2017, Khanama et al. 2012, van Jaarsveld et al. 2014). The leaves also contain photosynthetic pigments, including chlorophylls and carotenoids, which are considered highly beneficial to human health (Žnidarčič et al. 2011). A number of epidemiological studies have revealed that a diet rich in chlorophyll or carotenoids may be correlated with a diminished risk of several degenerative disorders, including cardiovascular diseases and various types of cancer (Boon et al. 2010, Sangeetha and Baskaran 2010). These preventive effects have been associated with their antioxidant activity, i.e. protecting cells and tissues from oxidative damage (Alvarez-Parilla et al, 2010, Liu 2013).

The plant's leaves are thin and flat, which facilitates better sunlight absorption for photosynthesis (Read and Stokes 2006, Onoda et al. 2011), but at the same time renders the delicate plant material vulnerable to various types of damage (Read and Stokes 2006, Onoda et al. 2008). Apart from static interactions, leaves are also subjected, throughout their development, to various dynamic twisting, bending and frictional forces. These may originate both from abiotic factors such as winds or precipitation but can also be due to biotic damage caused by feeding insects and herbivorous animals (Read and Stokes 2006, Read and Sanson 2003). For instance, damage suffered by Scorzonera hispanica leaves due to heavy rainfall takes the form of cracks in the vicinity of the leaf base and affect the adaxial part of the leaf (Chwil et al. 2015). Such damage may reduce the assimilative and yield-producing potential of the plant and deteriorate the quality of the leaves as edible parts of the plant. In order to reduce said damage, preserve leaf integrity, quality and durability, one should consider ways to improve the mechanical strength of the leaves.

The physical characteristics which are considered to be indicative of a given material's mechanical strength include its compressive strength, tensile strength and shear strength, stress relaxation, mechanical hysteresis, and Young's modulus (Mohsenin 1986). Young's modulus is a measure of material, including plant material, elasticity and is a basic physical value determined in the course of various strength tests. Furthermore, due to the parameter's independence of the tested specimen's geometric dimensions, it allows for a direct stiffness comparison between various materials (Mohsenin 1986).

The strength characteristics of plant leaves are usually determined based on three main types of mechanical tests - puncture test, shear test and tensile test (Onoda et al. 2011, Read and Sanson 2003). The tensile test is particularly useful in studies conducted on heterogenous plant material (Kohyama et al. 2008) as it may provide valuable information concerning mechanical characteristics, and also with regard to forces parallel to fibre alignment (Angeles et al. 2013, Kohyama et al. 2008). Single-axis tensile strength tests have been conducted to determine various strength parameters of e.g. cabbage leaves (Kohyama et al. 2008), lettuce 
(Newman et al. 2005), spinach (Watanabe et al. 2017, Tang et al. 2011), chives (Pinzón et al. 2013), as well as rosemary stems (Arevalo et al. 2013) and many other thin-layered plant materials (Gładyszewska 2007).

The method of pre-sowing seed refinement by way of laser light stimulation has been used mainly with a view to improving the seed germination rate, seedling sprout rate, and overall crop yield (Podleśna et al. 2015, Krawiec et al. 2015, Swathy et al. 2016). Some researchers argue that exposing seeds to light stimulation could improve the quality of yields, including the chemical composition of plants, e.g. by increasing the sugar content in sugar beet roots (Sacała et al. 2012), increase the content of minerals and specific protein in alfalfa (Ćwintal et al. 2010), or increase the content of chlorogenic acid responsible for aubergine fruit's antioxidative qualities (Swathy et al. 2016).

In terms of leaf vegetative resistance to conditions inhibiting growth, causing mechanical damage, and reducing the suitability of the leaf for consumption, it should be considered whether pre-sowing seed exposure to light stimulation could be used to improve the plant's qualitative characteristics in this respect.

The aim of the study was to determine the impact of pre-sowing He-Ne laser light stimulation of scorzonera seeds on the content of photosynthetic pigments in the obtained leaves and the mechanical strength of the same, as determined on the basis of Young's modulus.

\section{MATERIAL AND METHODS}

The research material consisted of 'Maxima' scorzonera leaves. The scorzonera plants were obtained from seeds treated prior to sowing with He-Ne laser light at a wavelength of $632.8 \mathrm{~mm}$, a surface power density of $5 \mathrm{~mW} \mathrm{~cm}^{-2}$, and an exposure time of 1, 5, 10, and $30 \mathrm{~min}$. (L1, L5, L10, L30), respectively. The control group leaves were harvested from non-stimulated plants. Laser light stimulation was provided using a device of our own design (Fig. 1), projecting laser light onto the seed dish from above. The field experiment was conducted at the Felin Experimental Farm of the University of Life Sciences in Lublin $\left(51^{\circ} 23^{\prime} \mathrm{N} 22^{\circ} 56^{\prime} \mathrm{E}\right)$ on a grey-brown podzolic soil developed from loess formations overlying chalk marls, with the grain size composition corresponding to that of weak silty loams. The seeds were sown on the $26^{\text {th }}$ of April 2013. The study entailed the determination of the content of photosynthetic pigments in scorzonera leaves and assessing the mechanical qualities of the same. The research material consisted of young leaves ( $3^{\text {rd }}$ fully developed leaf from the apical meristem). The leaves were harvested in the second half of August from four-month old plants.

The content of photosynthetic pigments (chlorophyll $a, b, a+b$, and carotenoids) in the leaves was determined spectrophotometrically. Chlorophylls and carotenoids were isolated from the leaves in darkness, using acetone containing $0.01 \% \mathrm{w} / \mathrm{v}$ of BHT 
(butylated hydroxytoluene). The UV-Vis spectra were measured using a double beam spectrophotometer Carry Bio 300, and the pigment concentration was calculated in accordance with the procedure published by Lichtenthalter and Buschmann (2001).

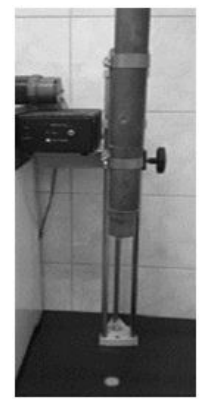

Fig. 1. Own-designed rig for subjecting seeds to laser light stimulation

Strength tests were conducted at a bench equipped with tensiometric instruments and software necessary for the determination of Young's modulus in accordance with the author's own method involving a visual analysis of the relative positions of random points placed on the studied material (random markers method) (Gładyszewska 2007). The benefit of the aforementioned method is that it allows one to disregard edge conditions by providing results that are independent of material deformations in the area of critical sections. The specimens prepared for laboratory testing were $50 \mathrm{~mm}$ long, dumb-bell shaped, with a stretched surface width of $20 \mathrm{~mm}$, cut out in such a way so that the midrib of the leaf was located at the symmetry axis of the dumb-bell. Specimen thickness was measured in 10 places using a micrometric screw with $0.01 \mathrm{~mm}$ increments. The prepared specimen was placed in the clamps of the testing machine and stretched, with a force increase rate of $0.13 \mathrm{~N} \mathrm{~s}^{-1}$. The moment of measurement initiation was preceded by a stage during which pulverised graphite markers were placed on the specimen using a special brush. The image of the stretched specimen was transferred via a dedicated camera to a computer analysing the changes in the relative spacing of the markers throughout the stretching test (Gładyszewska 2007, Gładyszewska et al. 2011). Each measurement series included 30 repetitions. The value of Young's modulus for each specimen was determined based on the tangent of the angle of inclination for the line corresponding to a single relationship:

$$
\varepsilon_{x}=f(\sigma)
$$

where: , $\varepsilon_{x}$-deformation of the specimen in the direction of the force $F, \sigma$-tension (MPa), $\sigma=\frac{F}{S}, F-$ stretching force acting on the specimen (N), $S-$ area of the specimen's cross-section $\left(\mathrm{mm}^{2}\right)$. 
The total value of the linear elasticity modulus $E$ was the averaged value of all individual measurements.

Statistical analyses of the results obtained from the tests were conducted with the use of StatSoft Inc. STATISTICA ver. 13.1 software. In isolated cases of inconsistency in the measurable variables with the assumptions necessary for the applicability of parametric statistical tests, the analysis of the obtained results was performed based on non-parametric tests. The analysis of the discrepancies in Young's modulus values $E$ between the respective groups (C, L1, L5, L10, L30) entailed the use of the Kruskal-Wallis ANOVA rank test and median test, followed by multiple comparisons of mean ranks from all tests at the level of significance of $\alpha=0.05$.

Furthermore, a statistical analysis was performed for the mean values of photosynthetic pigment content using an ANOVA analysis, LSD test for the respective study groups.

\section{RESULTS AND DISCUSSION}

Figure 2. presents Young's modulus median values of $E$ for scorzonera leaves relative to the time of pre-sowing seed exposure to He-Ne laser light. The statistical analysis revealed significant differences between the values of Young's modulus in the leaves of plants grown from non-stimulated seeds (C) and the leaves of plants grown from seeds stimulated with light prior to sowing. The lowest $E$ value of $2.89 \mathrm{MPa}$ was recorded for the control group (C). The leaves of plants grown from stimulated seeds were characterized by a higher mechanical strength, as expressed by the higher values of $E$ when compared to the control. The highest value of Young's modulus was observed for the leaves of plants grown from seeds exposed to laser light for a period of 10 minutes (L10). This measurement was nearly four times higher that the value observed in the control (Tab. 1, Fig. 2).

Table 1. Statistically significant differences between the homogeneous groups of Young's modulus and its dependence on seed exposure time to He-Ne laser light

\begin{tabular}{lccccc}
\hline \multicolumn{1}{c}{ Investigated } & \multicolumn{5}{c}{ Seed exposure time to He-Ne laser light } \\
\cline { 2 - 6 } \multicolumn{1}{c}{ feature } & $\mathrm{C}$ & L1 & L5 & L10 & L30 \\
\hline $\begin{array}{l}\text { Young's modulus } \\
\text { E (MPa) }\end{array}$ & d & c & c & a & b \\
\hline
\end{tabular}

L1, L5, L10, L30 - He-Ne laser light stimulation of scorzonera seeds with the exposure time of, respectively: 1 minute, 5 minutes, 10 minutes, 30 minutes, $\mathrm{C}$ - control; Different letters mean statistically significant differences between the homogeneous groups of Young's modulus at $p \leq 0.05$

In the case of scorzonera, the mechanical strength of the leaves determines their vulnerability to damage due to intensive rainfall and wind. This type of damage affects the base region of the leaf and results in the leaf cracking in the location of the vascular bundle (Chwil et al. 2015). This results in the death of the leaf and 
a reduction in the assimilative area of the plant, and consequently a reduced yield from the leaves and roots. An improvement in the mechanical strength of the leaves translates into better resistance to physical damage caused by both difficult environmental conditions and the later processing and handling of plant material.

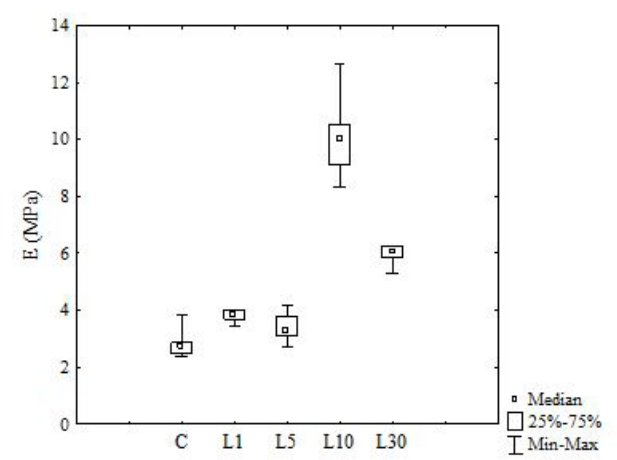

Fig. 2. Median of Young's modulus for the analysed scorzonera leaves. E (MPa) - Young's modulus; L1, L5, L10, L30 - He-Ne laser light stimulation of scorzonera seeds with exposure times of, respectively: 1 minute, 5 minutes, 10 minutes, 30 minutes, $\mathrm{C}$ - control

In the available literature, there are no studies concerning the effect of the pre-sowing treatment of seeds with laser light on the strength properties of leaves. Studies indicate that the values of Young's modulus for leaves depends primarily on the plant species, cultivar and growth phase. Angeles et al. (2013) determined the value of $E$ for the leaves of 4 plant species used in the preparation of tamale, a traditional Mexican dish. In the case of Calathea misantlensis and Canna indica the values of $E$ were within the range of approx. 16-18 MPa and 13-19 MPa, respectively, for the parallel and perpendicular direction of forces affecting the leaf. Young's modulus values for the cooking banana (Musa paradisiaca) leaves subjected to stretching forces in the direction of the midrib was approx. $213 \mathrm{MPa}$, while in the direction perpendicular to the same it was over 13 times lower. The lowest value of modulus $E$, regardless of the direction of the stress forces, was observed for Oreopanax capitatus and it was within the range of 4.7-4.9 MPa (Angeles et al. 2013). Kohyama et al. (2008) determined the value of the modulus $E$ for the leaves of 6 cabbage cultivars and obtained values within the ranges of approx. 2.6-3.25 MPa and approx. 1.52.6 MPa, respectively, for the parallel and perpendicular direction of forces acting on the leaf. Newman et al. (2005) measured Young's modulus values for lettuce and obtained results of approx. $8 \mathrm{MPa}$ for adult leaves and $2.4 \mathrm{MPa}$ for young seedlings.

Anten et al. (2010) observed in their research that subjecting the leaves of broadleaf plants (Plantago major) to mechanical stress (brushing) and wind did not significantly affect the value of Young's modulus as compared to non-stimulated leaves. In the case of spinach leaves, the linear elasticity modulus values were 
approx. 2.3 MPa, and for leaves subjected to blanching for differing periods of time, the value of $E$ was within the range from approx. $1.7 \mathrm{MPa}(10 \mathrm{~s})$ to $3.3 \mathrm{MPa}(40 \mathrm{~s})$ (Watanabe et al. 2017).

Figures 3-5 present values corresponding to the chlorophyll $a, b$, and $a+b$ content in scorzonera leaves relative to the time of exposure to He-Ne laser light stimulation. It was observed that exposing seeds to laser light for 1, 5 and $30 \mathrm{mi}-$ nutes had a significant impact in terms of increasing the content of chlorophyll $a, b$, and $a+b$ in the leaves as compared to the non-stimulated control. The best results were recorded for an exposure time of 1 minute, where the observed increase in chlorophyll $a, b, a+b$ content was, respectively, $18.3,17.9$, and $18.2 \%$. Increasing the exposure time to 10 minutes did not improve the content of said pigments.

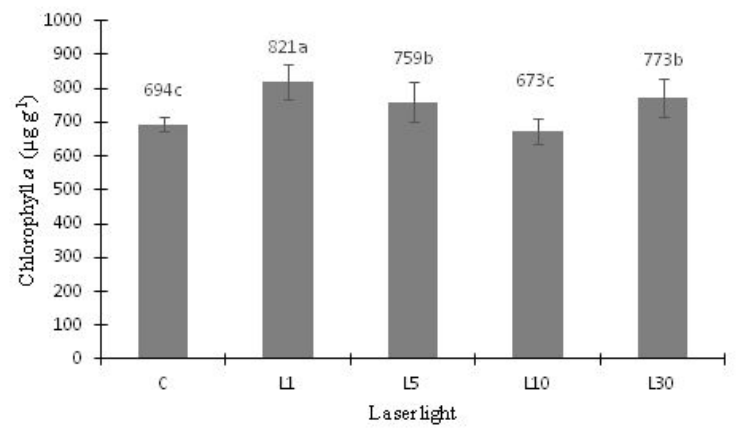

Fig. 3. Impact of seed exposure time to He-Ne laser light on the content of chlorophyll $a$ in scorzonera leaves. L1, L5, L10, L30 - He-Ne laser light stimulation of scorzonera seeds with an exposure time of, respectively: 1 minute, 5 minutes, 10 minutes, 30 minutes, $\mathrm{C}$ - control; Means with different letters are significantly different at $\mathrm{p} \leq 0.05$

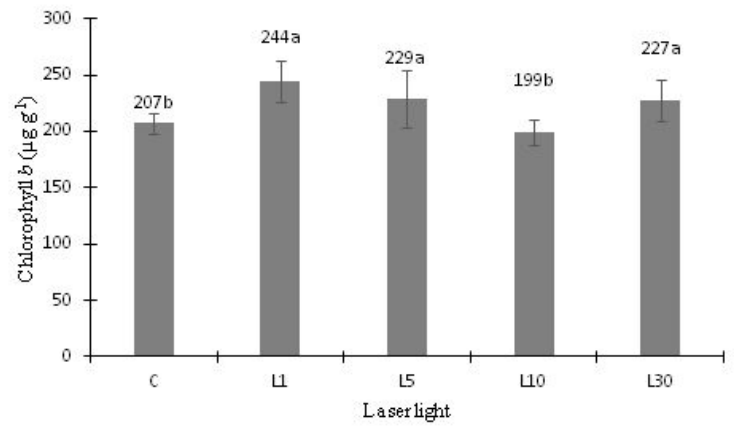

Fig. 4. Impact of seed exposure time to He-Ne laser light on the content of chlorophyll $b$ in scorzonera leaves. Explanations as under the Fig. 3.

It was noted that stimulating the seeds with laser light for 1, 5, and 30 minutes had a significant impact on the content of carotenoids in the resulting scorzonera leaves. The highest increase in this respect was observed in the leaves of plants 
grown from seeds stimulated for 1 minute and was $20.5 \%$ compared to the control. Leaves of plants grown from seeds stimulated for 10 minutes contained lower levels of carotenoids than those in the control (Fig. 6).

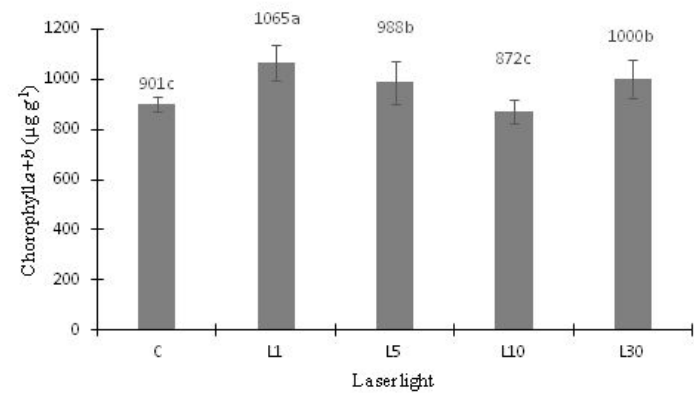

Fig. 5. Impact of seed exposure time to He-Ne laser light on the content of chlorophyll $a+b$ in scorzonera leaves. Explanations as under the Fig. 3.

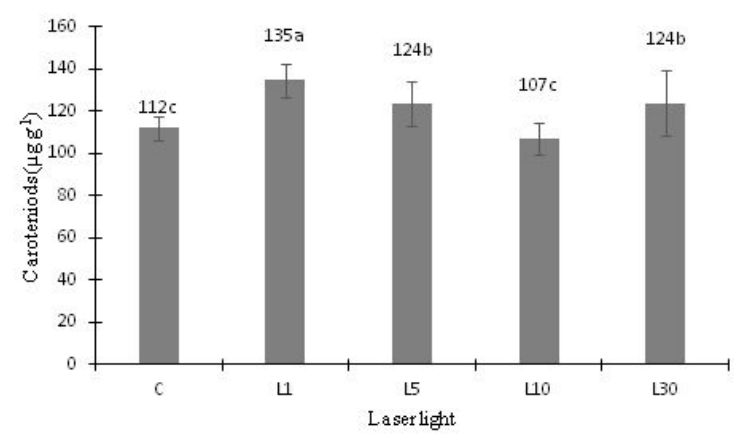

Fig. 6. Impact of seed exposure time to He-Ne laser light on the content of carotenoids in scorzonera leaves. Explanations as under the Fig. 3.

Studies conducted to date by various researchers have revealed that the pre-sowing stimulation of seeds with laser light tends to increase the content of photosynthetic pigments in leaves in the initial phase of plant growth. Asghar et al. (2016) reported a significant increase in chlorophyll $a, b$ and total chlorophyll content in young seedlings of soya grown from seeds exposed to He-Ne laser light at a wavelength of $632.8 \mathrm{~nm}$, surface power density of $1 \mathrm{~mW} \mathrm{~m}^{-2}$ and exposure time of 3 and $5 \mathrm{~min}$. Perveen et al. (2011) demonstrated the significant impact of the pre-sowing exposure of sunflower (Helianthus annus L.) seeds to He-Ne laser light on the increase in chlorophyll $a$ and $b$ content in young plants (30-day plants). In a study by Muthusamy et al. (2012), the exposure of aubergine (Solanum melongena $\mathrm{L}$.) seeds to $\mathrm{He}-\mathrm{Ne}$ laser light at $25 \mathrm{~J} \mathrm{~cm}^{-2}$ caused a significant increase in the content of chlorophyll $a$, total chlorophyll, and carotenoids in 30-day seedlings. 
Similar results were reported by Dziwulska-Hunek et al. (2016) in a study concerning the impact of laser light stimulation of seeds on the content of photosynthetic pigments in 8- and 30-day-old leaves of scorzonera of the 'Duplex' cultivar.

The available literature lacks any reference to studies concerned with the impact of light stimulation of seeds on chlorophyll and carotenoids content in the more advanced stages of plant growth and development, i.e. the stage at which plants are typically processed for consumption. The experiment described herein revealed the significant impact of this method of seed stimulation on the content of pigments in scorzonera leaves at the phase of edibility. The leaves obtained from non-stimulated seeds contained, on average, $694 \mu \mathrm{g} \mathrm{g}^{-1}-$ of chlorophyll $a$, $207 \mu \mathrm{gg}^{-1}$ - of chlorophyll $b$, and $112 \mu \mathrm{g} \mathrm{g}^{-1}$ - of carotenoids. The values are comparable to the content of the same pigments in parsley and common spinach respectively 630, 230, and $139 \mu \mathrm{g} \mathrm{g}^{-1}$ and 690,219, and $159 \mu \mathrm{g} \mathrm{g}^{-1}$ (Wieczorek and Wieczorek 2016), i.e. the species could be counted among the most common leaf vegetables. In the study described, the pre-sowing light exposure of seeds caused an increase in the total chlorophyll content of scorzonera leaves in the range of 9.7$18.2 \%$, while the content of carotenoids increased from 10.7 to $20.5 \%$ depending on the exposure time. Since the two substances are photosynthetic pigments, it may be assumed that the increase in their concentration may influence the intensity of photosynthesis and consequently allow for better yields. In the future, it will probably be necessary to carry out studies to verify this dependence.

Carotenoids and chlorophylls are natural antioxidants found in fruit and vegetables. They serve an important role in reducing oxidative damage to the human body resulting from the activity of reactive forms of oxygen (Liu 2013, AlvarezParilla et al. 2010). Based on the results of the aforementioned study, it may be concluded that the exposure of seeds to laser light increased the concentration of those pigments in the leaves of scorzonera, and consequently improved the antioxidative potential and health benefits of the plant.

\section{CONCLUSIONS}

The pre-sowing stimulation of seeds using He-Ne laser light led to an increase in the chlorophylls and carotenoids content of scorzonera leaves and an improvement of their mechanical strength. A significant increase in the content of photosynthetic pigments was observed in the leaves of plants grown from seeds stimulated for 1,5 , and 30 minutes. The stimulation of seeds for a period of 10 minutes had the best effect on the value of Young's modulus but that time of seed exposure caused a decrease in the photosynthetic pigments content of the leaves. The same time of seed exposure to laser 
light has an opposite effect on these two features. It is necessary to conduct a broader study to verify the results obtained. It will be interesting to determine whether the qualitative parameters studied correlate with the leaf and root crops of scorzonera.

\section{REFERENCES}

Alvarez-Parrilla E., De La Rosa L.A., Amarowicz R., Shahidi F., 2010. Antioxidant Activity of Fresh and Processed Jalapeño and Serrano Peppers. J. Agric. Food Chem., 59, 163-173, https://doi. org $/ 10.1021 /$ jf103434u.

Angeles G., Lascurain M., Davalos-Sotelo R., Zarate-Morales R.P., Ortega-Escalona F., 2013. Anatomical and physical changes in leaves during the production of tamales. Am. J. Bot., 100(8), 1509-1521, https://doi.org/10.3732/ajb.1200578

Anten N.P.R., Alcalá-Herrera R., Scieving F., Onoda Y., 2010. Wind and mechanical stimuli differentially affect leaf traits in Plantago major. New Phytol., 188, 554-564, https://doi.org/ 10.1111/j.1469-8137.2010.03379.x

Arévalo C.A., Castillo B., Londoño M.T., 2013. Mechanical properties of rosemary (Rosmarinus afficinalis L.). Agron. Colomb., 31(2), 201-207.

Asghar T., Jamil Y., Iqbal M., ul-Haq Z., Abbas M., 2016. Laser light and magnetic field stimulation effect on biochemical, enzymes activities and chlorophyll contents in soybean seeds and seedlings during early growth stages. J. Photochem. Photobiol. B., 165, 283-290, https://doi. org/10.1016/j.jphotobiol.2016.10.022

Boon C.S., Mcclements D.J., Weiss J., Decker E.A., 2010. Factors influencing the chemical stability of carotenoids in foods. Crit. Rev. Food Sci. Nut., 50(6), 515-532,.https://doi.org/ $10.1080 / 10408390802565889$

Chwil M., Krawiec M., Krawiec P., Chwil S., 2015. Micromorphology of the epidermis and anatomical structure of the leaves of Scorzonera hispanica L. Acta Soc. Bot. Pol., 84 (3), 357-367, https:// doi.org/10.5586/asbp.2015.033

Ćwintal M., Dziwulska-Hunek A., Wilczek M., 2010. Laser stimulation effect of seeds on quality of alfalfa. Int. Agrophys., 24(1), 15-19.

Dolota A., Dąbrowska B., 2004. The nutritive value of the leaves of several scorzonera (Scorzonera hispanica L.) cultivars. Folia Universitatis Agriculturae Stetinensis. Agricultura, 239(95), 63-68.

Dziwulska- Hunek A., Krawiec M., Sujak A., 2016. Laser light stimulation on Scorzonera hispanica L. seeds germination, field emergence and photosynthetic pigments content. J. Hort. Res., 24(1), 57-62, https://doi.org/10.1515/johr-2016-0007

Gładyszewska B., 2007. A Method of Investigation of Chosen Mechanical Properties of Thin-Layered Biological Materials (in Polish). Agricultural University Press, Lublin, Poland.

Gładyszewska B., Baranowski P., Mazurek W., Ciupak A., Woźniak J., 2011. Radiation temperature of tomatoes and mechanical properties of their skin. Int. Agrophys., 25, 131-139.

Jiménez-Aguilar D.M., Grusak M.A., 2017. Minerals, vitamin C, phenolics, flavonoids and antioxidant activity of Amaranthus leafy vegetables. J. Food. Compost. Anal., 58, 33-39, https://doi.org/ 10.1016/j.jfca.2017.01.005

Khanama U.K.S., Oba S., Yanase E., Murakami Y., 2012. Phenolic acids, flavonoids and total antioxidant capacity of selected leafy vegetables. J. Funct. Foods, 4(4), 979-987, https://doi.org/ 10.1016/j.jff.2012.07.006 
Kohyama K., Takada A., Sakurai N., Hayakawa F., Yoshiaki H., 2008. Tensile test of cabbage leaves for quality evaluation of shredded cabbage. Food Sci. Technol. Res., 14(4), 337-344, https://doi. org/10.3136/fstr.14.337

Krawiec M., Dziwulska-Hunek A., Sujak A., Palonka S., 2015. Laser irradiation effects on scorzonera (Scorzonera hispanica L.) seed germination and seedling emergence. Acta Sci. Pol. Hort. Cultus., 14(2), 145-158.

Lichtenthaler H.K., Buschmann C., 2001. Chlorophylls and Carotenoids: Measurement and Characterization by UV-Vis Spectroscopy. In: Current Protocols in Food Analytical Chemistry. Supplement 1, Wiley \& Sons. Inc., USA:F4.3.1-F4.3.8, https://doi.org/10.1002/0471142913. faf0403s 01

Liu R.H., 2013. Health-promoting components of fruits and vegetables in the diet. Adv. Nutr., 4, 484S-493S, https://doi.org/10.3945/an.112.003517

Mohsenin N.N., 1986. Physical properties of plant and animal materials. I. Structure, physical characteristic and mechanical properties. New York, London, Paris: Gordon and Breach Science Publishers.

Muthusamy A., Kudwa P.P., Prabhu V., Mahato K.K., Babu V.S., Rao. M.R., Gopinath P.M., Satyamoorthy K., 2012. Influence of Helium-Neon Laser irradiation on seed germination in vitro and physic-biochemical characters in seedlings of brinjal (Solanum melongena L.) var. Mattu Gulla. Photochem. Photobiol., 88(5), 1227-1235, https://doi.org/10.1111/j.1751-1097.2012.01162.x

Newman J.M., Hilton H.W., Clifford S.C., Smith A.C., 2005. The mechanical properties of lettuce: A comparison of some agronomic and postharvest effects. Journal of Materials Science, 40, 11011104, https://doi.org/10.1007/s10853-005-6923-3

Onoda Y., Schieving F., Anten N.P.R., 2008. Effects of light and nutrient availability on leaf mechanical properties of Plantago major: A conceptual approach. Ann. Bot., 101, 727-736, https://doi. org/10.1093/aob/men013.

Onoda Y., Westoby M., Adler P.B., Choong A.M.F., Clissold F.J., Cornelissen J.H.C., Diaz S., Dominy N.J., Elgart A., Enrico L., Fine P.V.A., Howard J.J., Jalili A., Kitajima K., Kurokawa H., McArthur C., Lucas P.W., Markesteijn L., Perez- Harguindeguy N., Poorter L., Richards L., Santiago L.S., Sosinski jr E.E., Van Bael S.A., Warton D.I., Wright I.J., Wright S.J., and Yamashita N., 2011. Global patterns of leaf mechanical properties. Ecol. Lett., 14, 301-312, https://doi.org/10.1111/j.1461-0248.2010.01582.x

Perveen R., Jamil Y., Ali Q., Ashraf M., Ali Q., Iqbal M., Ahmad M.R., 2011. He-Ne laserinduced improvement in biochemical, physiological, growth and yield characteristics in sunflower (Helianthus annus L.). Photochem. Photobiol., 8, 1453-1463, https://doi. org/10.1111/j.1751-1097.2011.00974.x

Pinzón A.M., Castillo B., Londoño M.T., 2013. Characterization of the mechanical properties of chives (Allium schoenoprasum L.). Agron. Colomb., 31(1), 83-88.

Podleśna A., Gładyszewska B. Podleśny J., Zgrajka W., 2015. Changes in the germination process and growth of pea in effect of laser seed irradiation. Int. Agrophys., 29(4), 485-492, https://doi. org/10.1515/intag-2015-0054

Read J., Sanson G.D., 2003. Characterizing sclerophyll: the mechanical properties of a diverse range of leaf types. New Phytol., 160, 81-99, https://doi.org/10.1046/j.1469-8137.2003.00855.x

Read J., Stokes A., 2006. Plant biomechanics in an ecological context. Am. J. Bot., 93(10), 1546-1565, https://doi.org/10.3732/ajb.93.10.1546

Sacała E., Demczuk A., Grzyś E., Prośba-Białczyk U., Szajsner H., 2012. Impact of pre-sowing laser irradiation of seeds on sugar beet properties. Int. Agrophys., 26(3), 295-300, https://doi. org/10.2478/v10247-012-0042-6 
Sangeetha, R. K., Baskaran V., 2010. Carotenoid composition and retinol equivalent in plants of nutritional and medicinal importance. Efficacy of b-carotene from Chenopodium album in retinol-deficient rats. Food Chem., 119, 1584-1590, https://doi.org/10.1016/j.foodchem.2009.09.047

Swathy S.P., Kiran K.R., Rao M.S., Mahato K.K., Rao M.R., Satyamoorthy K., Muthusamy A., 2016. Responses of He-Ne laser irradiation on agronomical characters and chlorogenic acid content of brinjal (Solanum melongena L.) var. Mattu Gulla. J. Photochem. Photobiol. B, 164, 182-190 https://doi.org/10.1016/j.jphotobiol2016.09.0101011-1344.

Tang X., Mo C. Y., Chan D. E., Peng Y., Qin J., Yang C., Kim M. S., Chao K., 2011. Physical and mechanical properties of spinach for whole-surface online imaging inspection. Proc. SPIE 8027, Sensing for Agriculture and Food Quality and Safety III, 802711, https://doi.org/10.1117/12.884892

van Jaarsveld P., Faber M., van Heerden I., Wenhold F., van Rensburg W. J., van Averbeke W., 2014. Nutrient content of eight African leafy vegetables and their potential contribution to dietary reference intakes. J. Food. Compost. Anal., 33, 77-84, https://doi.org/10.1016/j.jfca.2013.11.003

Watanabe T., Ando Y., Orikasa T., Shiina T., Kohyama K., 2017. Effect of short time on the mechanical fracture and electrical impedance properties of spinach (Spinacia oleracea L.). J. Food Eng., 194, 9-14, https://doi.org/10.1016/j.jfoodeng.2016.09.001

Wieczorek J., Wieczorek Z., 2016. Above ground parts of popular vegetables as a source of carotenoids and chlorophyll in food (in Polish). Bromat. Chem. Toksykol., XLIX, 422-426.

Žnidarčič D., Ban D., Šircelij H., 2011. Carotenoid and chlorophyll composition of commonly consumed vegetables in Mediterranean countries. Food Chem., 129(3), 1164-1168, https://doi. org/10.1016/j.foodchem.2011.05.097 